\title{
OS ESTUDOS DE COMUNIDADES NO BRASIL*
}

\author{
Oracy Nogueira \\ Professor da Escola de Sociologia e Política de São Paulo
}

Por "estudos de comunidades" temos em vista aquêles levantamentos de dados sôbre a vida social em seu conjunto, relativos a uma área cujo âmbito é determinado pela distância a que se situam nas várias direções, os moradores mais afastados do centro local de maior densidade demográfica, havendo entre os moradores do núcleo central e os da zona circunjacente, assim delimitada, uma interdependência direta para a satisfação de, pelo menos, parte de suas necessidades fundamentais.

As relações sociais - no sentido mais amplo dêste adjetivo - são mais freqüentes e intensas entre os integrantes da mesma comunidade que entre os de duas diferentes comunidades, mesmo vizinhas. Os membros de uma comunidade se distinguem, portanto, pelo seu maior conhecimento recíproco, pela participação num repertório comum de experiências relativas ao habitat, às pessoas e instituições locais e pela conseqüente consciência grupal que os contrasta com outros grupos populacionais .

\section{Relação dos estudos de comunidades realizados ou em andamento no Brasil}

Embora a designação se possa aplicar com igual, se não com maior propriedade aos estudos de agrupamentos indígenas, mais ou menos isolados, drtados de língua e instituições peculiares, o presente relatório se limitará à consideração dos estudos de agrupamentos de população situados em diferentes pontos do País, porém, que, não obstante tôdas as peculiaridades locais, estão integradas na estrutura social nacional, participando das mesmas instituições básicas e do lastro comum de tradições que caracterizam a nação. Ao estudo de grupos populacionais integrados em complexas estruturas nacionais, mais que ao de grupos indígenas relativamente isolados, é que se tem aplicado a designação; e a aplicação de tal perspectiva metodológica, no caso dos primeiros, suscista problemas e dificuldades especiais.

(*) Comunicação feita na 1a. Reunião Brasileira de Antropologia, Rio de Janeiro, 8-14 de novembro de 1953. 
Quatro estudos de comunidades, realizados no Brasil, já se encontram publicados:

1) o de Emílio Willems, Cunha, Tradição e Transição em uma Cultura rural do Brasil, São Paulo, Diretoria de Publicidade Agrícola da Secretaria da Agricultura, 1947;

2) o de Lucila Herrmann, "Evolução da Estrutura Social de Guaratinguetá num Período de Trezentos Anos", Revista de Administração (Instituto de Administração, Faculdade de Ciências Econômicas e Administrativas, Universidade de São Paulo), Ano II, Março-Junho de 1948, N. ${ }^{\circ}$ 5-6, páginas 1-326;

3) o de Donald Pierson, Cruz das Almas, A Brazilian Village, Washington, Smithsonian Institution, Institute of Social Anthropology, Publication N. ${ }^{\circ}$ 12, 1951 ;

4) o de Charles Wagley, Amazon Town, A Study of Man in the Tropics, New York, The Macmillan Company, 1953.

Em vias de publicação ou em conclusão, podem ser mencionados os seguintes:

5-6-7) os três estudos em diferentes zonas ecológicas do Estado da Bahia, iniciados em julho de 1950, com prosseguimento durante o ano de 1951, em programa de cooperação entre a Secretaria da Educação e Saúde do Estado da Bahia e o Departamento de Antropologia da Columbia University, de New York, sob a direção de Charles Wagley, Thales de Azevedo e Luiz A. Costa Pinto ${ }^{1}$;

8-9-10-11-12) o estudo de cinco pares de comunidades, no vale do Rio São Francisco, sob a direção de Donald Pierson e sob o patrocínio da Comissão do Vale do São Francisco;

13) o estudo de Oracy Nogueira, no município de Itapetininga, no Estado de São Paulo;

14) c estudo de Bernard J. Siegel, de uma comunidade nas vizinhanças das capital do Estado de São Paulo²;

15) o estudo de Esdras Borges Costa, numa vila situada na Ilha de Santa Catarina, no Estado do mesmo nome.

Temos, ainda, notícia de 2 estudos em andamento;

16) o de Cabo Frio, no Estado do Rio, com a participação de D. Heloisa Alberto Torres e outros técnicos, sob o patrocínio do Museu Nacional;

17) o de Chonim, no Estado de Minas Gerais, por Alfonso Trujillo Ferrari.

Os $17^{2 a}$ estudos se referem, pois, a comunidades localizadas desde a bacia amazônica, ao norte (Estado do Pará), até o Estado de Santa Catarina, ao sul. Com efeito, sãc os seguintes os Estados em que se encontram 
:as comunidades já estudadas ou em estudo: Pará, Pernambuco, Alagoas, Bahia, Minas Gerais, Rio de Janeiro, São Paulo e Santa Catarina.

Dos estudos publicados, o de Emílio Willems diz respeito a um município de 27.000 habitantes, dos quais 1.500 vivem na sede; o de Lucila Herimann, a um município de 30.000 , dos quais 15.000 vivem na parte urbana; o de Donald Pierson, a uma vila, cujo distrito compreende 2.700 habitantes, dos quais três centenas vivem na sede; o de Charles Wagley, a um município de 6.000 habitantes, dos quais 500 vivem na sede, à qual estão diretamente ligados outros 1.500 , o que dá para a "comunidade", pròpriamente dita, 2.000. As comunidades estudadas na Bahia, no programa da Secretaria da Educação e Saúde e Columbia University, contam, cada qual, com cêrca de 1.500 a 2.500 habitantes na sede e de 4.000 a 5.000 , no total ${ }^{3}$. A população da sede, nas comunidades estudidas no vale do Rio São Francisco, sob a direção de Donald Pierson, varia de cêrca de 700 a cêrca de 4.000 , enquanto a população total vai de, aproximadamente, 9.000 a 38.000 . A comunidade estudada por Oracy Nogueira conta com cêrca de 35.000 habitantes, dos quais 15.000 na parte urbana; e a de Bernard J. Siegel, com 20.000 e 900 habitantes, respectivamente; a de Edras Borges Costa, cêrca de 2.500, dos quais 1.000 na sede. A comunidade em estudo pela equipe do Museu Nacional, no Estado do Rio, conta com um total de cêrca de 3.000 habitantes $^{4}$; a de Alfonso Trujillo Ferrari, cêrca de 3.000, ao todo, e 400 na sede.

Enfim, as comunidades estudadas ou em estudo compreendem desde simples sedes de distritos, com algumas centenas de habitantes, até seäes de comarca com 15.000 habitantes urbanos, indo os habitantes rurais de 2 até aproximadamente 40 milhares. A economia dessas comunidades é predominantemente rural, compreendendo a agricultura, a pecuária e a indústria extrativa vegetal e animal; porém, no total da população colhida pelos estudos referidos, as ocupações urbanas - a burocracia, o proletariado, as chamadas profissões liberais, o comércio, etc. - estão reinterêsse, da energia e dos recursos com que contarão os especialistas que, lhes cabe no conjunto da população nacional.

Cremos que as informações até aqui apresentadas bastam para mostrar a importância que vão assumindo os chamados "estudos de comunidades", no Brasil, verdadeiro movimento intelectual, o mais vigoroso, até o momento, na história da pesquisa sociológica no País e, ao que tudo indica, com tendência a absorver uma parte cada vez mais considerável do interêsse, da energia e dos recursos com que contarem os especialistas, que, no futuro imediato, se empenharem no levantamento de dados sistemáticos para o conhecimento da realidade nacional.

Vejamos, pois, no âmbito nacional, o que se espera desta perspectiva metcáológica, seja do ponto de vista teórico, seja do ponto de vista prático. 


\section{Contribuição teórica dos estudos đe comunidades}

Do ponto de vista teórico, espera-se que os estudos de comunidades, à medida em que se multipliquem, forneçam um complemento e, em certo sentido, um corretivo aos estudios de caráter analítico, por proverem uma visão de conjunto, funcional, da vida social, através da consideração e interpretação de dados sincrônicos e diacrônicos referentes ao mesmo locus geográfico, isentos, pois, tanto quanto possível, quer da interpolação de dados reais extra-locais, quer do preenchimento de lacunas do material por via de conjetura.

Além disso, trazendo ao primeiro plano a observação direta da vida dos indivíduos, com seu comportamento verbal e suas atitudes, sua atuação recíproca, seu comportamento tradicional e suas improvisações, suas convicções e suas racionalizações, os estudos de comunidades desvendam um importante aspecto da realidade social que ou escapa de todo ou é minimizado quando se adotam outras técnicas ou perspectivas que levam a umá apreensão dessa realidade pelos seus aspectos mais externos e quantitativos. Em cutras palavras, os estudos de comunidades permitem um exame mais adequado das manifestações subjetivas e inter-individuais da vida social, revelando a tendência do grupo a perpetuar seus valores tradicionais ou a abandoná-los e a substituí-los por outro sistema de valores; enfim, a reproduzir a própria vida social, indefinidamente, tal qual é, ou a deixá-la mudar, quer numa atitude de indiferença ou mero consentimento, quer pelo empenho consciente em prol do advento de novas condições de vida vislumbradas e desejadas.

\section{Contribuição prática dos estudos de comunidades}

Do ponto de vista prático, espera-se que os estudos ide comunidades, contribuindo para um conhecimento mais aprofundado e mais minucioso da realidade nacional, permitam uma eficiência maior ao trabalho de todos aquêles técnicos que, pelo caráter de suas atividades, são, ao mesmo tempo, agentes de mudança social e cultural: o agrônomo, o médico, especialmente o sanitarista, o educador e outros. A visão funcional que os estudos de comunidades proporcionam da vida social parece sugerir espontaneamente a necessidade de uma ação coordenada e cooperativa dêsses diferentes especialistas, quando tenham de atuar na mesma área e sôbre o mesmo grupo populacional.

Além do exposto, pode-se esperar que os estudos de comunidades, suscitando no espírito dos técnicos uma atitude mais compreensiva em relação às populações sôbre as quais tenham de atuar, os libertem, tanto quanto possível, de preconceitos que dificultam o desenvolvimento de uma recíproca simpatia, sem a qual tantas intençc̃es generosas se retraem ao primeiro obstáculo, cedendo lugar a manifestações de impaciência e irritação, de decepção e derrotismo. 
Até aqui, nossas referências têm sido ao que se pode esperar, sob - ponto de vista prático, dos estudos de comunidades, tendo-se em mira a atuação idos técnicos que, pelo caráter de suas atividades, são, ao mesmo tempo, agentes de mudança social e cultural. Não ha dúvida, porém, quanto ao fato de que a atuação dêsses técnicos pressupõe um planejamento para cujo sucesso também é de se esperar que os estudos de comunidades venham a contribuir considieràvelmente.

Os estudos de comunidades oferecerão ao administrador, ao político, ao homem de gabinete, aos habitantes das capitais e das grandes cidades, um quadro realista da vida dos pequenos e rústicos aglomerados do interior e da população rural, mostranddo o seu lado dramático e humano, seus problemas e suas dificuldades, suas condições reais e suas aspirações, seus recursos e sua experiência.

Em outras palavras, à medida em que se multiplicarem, em que se divulgarem seus resultados e se obtiver, através de sua síntese, uma visão panorâmica mais adequada dia realidade nacional, os estudos de ccmunidades poderão contribuir para uma correção parcial da tendência político-administrativa de se concentrarem os recursos disponíveis na solução dos problemas que afetam as populações dos centros de maior densidade, em detrimento dos que afetam a população rural e a dos menores e mais afastados núcleos demográficos.

Enfim, os estudos de comunidades já realizados ou em andamento têm revelado de modo insofismável que o desenvolvimento da produção, a melhoria das condições de saúde e educacionais, a curto prazo, sòmente se pode obter com a introdução de novos recursos na comunidade.

\section{Objeções teóricas aos estudos de comunidades}

A principal objeção que se pode fazer aos estudos de comunidades, do ponto de vista teórico, consiste na crítica já clássica de Durkheim ao método monográfico. Assim, a visão de conjunto da vida social de qualquer agrupamento humano de que até aqui temos falado está sujeita, necessàriamente, a um limite. Não se pode colher informações ou dados indefinidamente. Surge, pois, o problema de saber quais os dados a serem selecionados dentre a infinidade de dados possíveis.

A objeção é bastante séria e indica que não se pode colher daijos a esmo, sem preocupação com um quadro teórico ou com hipóteses mais ou menos definidas. Variarão, portanto, os estudos de comunidades com a formação teórica e geral dos diferentes pesquisadores. Com efeito, se dois pesquisadores estudarem uma mesma comunidade, no mesmo períono, porém inảependentemente, os resultados, provàvelmente, serão diversos.

A resposta que se pode dar a esta objeção é que o pesquisador, dotado de uma formação sistemática, há de estar ao par do repertório teó- 
rico das diferentes ciências sociais e dos resultados de estudos anteriores realizados quer através da mesma perspectiva, quer sob outra orientação. Além disso, há que distinguir duas ordens de dados que a pesquisa poderá trazer à tona: 1) dados singulares, que se referem a situações definidas e únicas, de caráter estritamente descritivo; e 2) dados genéricos, que se referem a situações típicas, relativamente permanentes ou recorrentes. Uma permanência suficientemente longa em qualquer comunidade permitirá levantar dados da segunda categoria, que são os que mais interessam do ponto de vista científico.

Outra objeção aos estudos de comunidades consiste em negar que as conclusc̃es a que êles levem se baseiem exclusivamente no material colhido. A esta objeção se pode dar uma resposta análoga à anterior. Tal como em outros domínios científicos, nas ciências sociais, igualmente, cada tentativa de avanço repousa não apenas na pesquisa atual, mas em todo o repertório anterior de conhecimentos. Assim, os resultados de um estudio de comunidade ou: 1) concordam com os de estudos análogos anteriores e se harmonizam com o repertório anterior de conhecimentos; ou 2) contradizem os resultados de pesquisas anteriores, exigindo confirmação posterior para a conseqüente extensão ou modificação daquele repertório de conhecimentos.

Enfim, outra resposta que se pode aplicar a ambas as objeções mencionadas está em que não se pretende assentar as ciências sociais nem exciusivamente nos estudos de comunidades, nem exclusivamente em estudos realizados sob outras perspectivas. No repertório comum de cada uma dessas ciências, os conhecimentos resultantes de estudos de comunidades terão de ser integrados com os resultantes de pesquisas em que se tenham empregado outros recursos.

Sem dúvida nenhuma, a ortodoxia no emprego da perspectiva de pesquisa de que estamos tratando pode levar a trabalhos de nível meramente descritivo e, portanto, cientificamente improfícuos. Ademais, o emprêgo indiscriminado e ex:lusivo desta perspectiva pode levar ao escamoteamento de importantes fenômenos e a uma visão deformada da realidade social, especialmente quando se leva ao exagêro o artifício de considerar isolada e fechada em si mesma uma comunidade que, não obstante viverem seus componentes em interação mais intensa e em mais íntima dependência entre si, está, todavia, integrada numa estrutura social mais ampla e mais complexa, da qual tanto ou mais que de si mesma depende o seu destino.

Assim, o âmbito de muitos fenômenos ultrapassa os limites locais, podendo cobrir tôda uma região, todo o território nacional e mesmo ultrapassar os limites dêste; a gênese de muitos fenômenos é exterior à comunidade. 


\section{O problema da representatividade nos estudos de comunidades}

Uma comunidade pode ser escolhida para estudo pelo simples fato de não ter sido estudada anteriormente. Neste caso, o problema da representatividade se reduz à determinação do tipo a que pertence $e$ a cujos exemplares se poderão aplicar as generalizações resultantes.

Além disso, pode uma comunidade ser escolhida para estudo porque o seu conhecimento convém ao esclarecimento de determinado problema. Neste caso, a formulação do problema precede à seleção da comunidade. $O$ problema pode consistir em se querer conhecer a vida social de uma determinada região ou de uma área cultural; ou em se pretender fazer um estudo de contactos inter-raciais; de assimilação ou aculturação; de uma comunidade rural que tenha passado a sofrer o impato de uma organização industrial próxima; de um grupo isolado a que uma estrada recém-construída tenha colocado súbitamente em contacto com outras aglomerações maiores, etc.

Quando o problema precede a escolha da comunidade, o preenchimento de certos critérios de representatividade é condição que se impõe por si mesma.

De um modo geral, as comunidades em estudo ou já estudadas, no Brasil, têm sido escolhidas em função de problemas prèviamente formulados: Emílio Willems escolheu Cunha e Donald Pierson a vila de "Cruz das Almas", o primeiro por desejar conhecer o processo de mudança de uma comunidade cujo grau de isolamento era considerável até há poucos anos, quando o advento de uma estrada mais eficiente e de meios de transporte mais modernos veio pô-la em contacto mais estreito e freqüente com outras populações; o segundo, por considerar uma povoação essencial. mente rural, relativamente isolada dos centros industriais, como representativa da maior parte da população brasileira; os trabalhos da Bahia foram idealizados tendo-se em vista, pelo estudo intensivo de três comunidades em três áreas ecológicas láistintas do Estado e pelo estudo complementar de outras três comunidades menos estáveis, nas mesmas regiões, obter um conhecimento da vida social e de sua tendência à mudança, útil ao planejamento de medidas eiducacionais e sanitárias; semelhante orientação foi adotada no planejamento dos estudos do vale do São Francisco; Charles Wagley escolheu, no Estado do Pará, à margem do Rio Amazonas, uma comunidade representativa das condições de vida da região, visando, igualmente, ao provimento de dados para a adoção de medidas educacionais e sanitárias; Esidras Borges Costa procurou uma comunidade remanescente da colonização açoriana com o fim de conhecer a influência dêste grupo populacional na formação social do sul do País; Oracy Nogueira escolheu uma comunidade onde fôsse possível acompanhar o povoamento e o desenvolvimento da estratificação social desde o século XVIII até o presente, sendo, portanto, ao mesmo 
tempo, uma comunidade "antiga" e "modernizada", isto é, constantemente afetada pelos fatôres de mudança que atuam nos pontos mais ativos do país, porém não demasiadamente complexa, pelo volume de. população, de modo a impossibilitar estudo desta natureza; procurou. Bernard J. Siegel uma comunidade situada nas imediações de um centro metropolitano cujo impacto viesse afetando a vida local de modo. cada vez mais sensível.

\section{Tendências dos estudos de comunidades no Brasil}

Não obstante o que possa haver de comum entre os estudos já publicados e os por publicar, no país, certas diferenças de orientação parecem visíveis: em alguns, é nítida a ênfase no estilo descritivo e na restrita consideração dos dacios atuais e locais, como sucede com o trabatho de Emílio Willems sôbre Cunha; no estudo de Lucila Herrmann sôbre Guaratinguetá, há uma ênfase no desenvolvimento histórico, através de vários "cortes transversais" pelos quais a autora procura expôr os diferentes aspectos da vida local em períodos sucessivos até chegar à atualidade; semelhantemente, no trabalho de Oracy Nogueira, ainda não publicado, considerável ênfase é posta no desenvolvimento histórico; uma tendência típica que talvez se possa apontar é a de fazer da comunidade em estudo o foco de atenção, por assim dizer, para o conhecimento de tồla a região de que faz parte, o que se observa nos estudos da Bahia, nos do vale do São Francisco e no de Wagley na Amazônia .

Enfim, nos estudos arrolados, três tendências principais se fazem notar: 1) a de dar ênfase aos aspectos locais e atuais, numa exageração do grau de isolamento da comunidade; 2) a de dar ênfase ao desenvolvimento histórico, com a consideração simultânea das condições atuais; e 3) a de estudar a vida social da comunidade e as condições ecológicas da região como dois aspectos interdepencientes da mesma realidade.

O estudo de Charles Wagley, recentemente publicado, sôbre a comunidade amazônica, parece combinar, com bastante equilíbrio, a consideração dos dados históricos com a dos relativos à ecologia regional e a dos referentes à vida atual e local, cuja ligação com o exterior (Belém, por exemplo) não é descurada. Talvez seja esta a orientação mais recomendável por ser a que mais condiz com o caráter monográfico dos estudos de comunidades. Esta será mais uma razão para que tais estudos sejam antes trabalhos de equipes, constituídas estas de elementos altamente capacitados e especializados, e não simples tarefas individuais.

Finalmente, se a realização de um estudo de comunidade mediante a aplicação de um esquema formal preconcebido e não ajustado à rea- 
lidade levará a resultados improfícuos, não menos verdadie é que os estudos monográficos, tomadas as devidas precauções, são compatíveis com as mais variadas perspectivas teóricas ${ }^{6}$.

Lembremos, mais uma vez, que êste tipo de estudo - o de comunidade, em que a atenção do investigador se focaliza na teia de relações humanas contidas numa área local bem determinada - e o tipo de trabalho com que nos habituaram os que se dedicam à história econômica, social e política e, em geral, os ensaistas, não se excluem mùtuamente, mas antes se completam. Muitos estudos de comunidades não teriam sentido, se não pelo fato de colocarem sob uma diferente perspectiva hipóteses surgidas e desenvolvidas através de estudos feitos com outra orientação.

\section{NOTAS}

(1) Cf. Charles Wagley, Thales de Azevedo e Luiz A. Costa Pinto, Uma Pesquisa sôbre a Vida Social no Estado da Bahia, Bahia, Secretaria da Educação e Saúde, Publicações do Museu do Estado, N. ${ }^{\circ} 11,1950$. Estava esta comunicação redigida, quando fomos informados, neste recinto, pelo Prof. Thales de Azevedo, ter sido realizado, no mesmo programa, um quarto estudo, em diferente área ecológica do Estado.

(2) Cf. Bernard J. Siegel, "Algumas considerações sôbre o estudo de uma comunidade brasileira, Sociologia, Vol. XII, N. 2, Maio de 1950, páginas $148-160$.

(2 A) 18 estudos com o acréscimo do referido pelo Prof. Thales de Azevedo.

(3) Cf. Charles Wagley, Thales de Azevedo e Luiz A. Costa Pinto, Uma Pesquisa sôbre a Vida Social no Estado da Bahia, já citado; e Charles Wagley, editor, Races et Classes dans le Brésil Rural, Unesco, 1951. A sede da comunidade cujo estudo foi incluído no programa posteriormente, segundo informa o Prof. Thales de Azevedo, tem de 4.001 a 5.000 habitantes.

(4) Informação do Dr. Carl Withers. Não foi possivel estimar a população de sede.

(5) A monografia estrangeira com a qual tais estudos mais se assemelham talvez seja a de Everett C. Hughes, French Canada in Transition.

(6) Assim, as criticas de Caio Prado Junior ao trabalho de Emílio Willems atingem ao trabalho em si e não ao "método" empregado como pretendeu o primeiro. Cf. "Métodos sociológicos", Fundamentos, São Paulo, Dezembro de 1948, Janeiro de $1949, \mathrm{~N}^{\circ} \mathrm{s}$. 7-8, páginas 23-30. 